\title{
Implantação do sistema de governança na Universidade Federal do Ceará na percepção dos gestores
}

Implementation of the governance system in the Federal University of Ceará in the perception of managers

\author{
Ruth Carvalho de Santana Pinho ${ }^{1}$ \\ Maria de Fátima Teixeira Brasil ${ }^{2}$
}

\section{RESUMO}

Este estudo tem o objetivo de analisar a implantação do Sistema Governança na Universidade Federal do Ceará (UFC). A instauração da Governança emana de novas práticas que tendem a mudar o foco da gestão, inclusive nas instituições da Administração Pública brasileira, voltando-o para os interesses dos usuários. Esta configura uma pesquisa de natureza qualitativa-quantitativa, descritiva quanto aos objetivos, por intermédio de um estudo de caso realizado na UFC. A respeito dos procedimentos técnicos foram utilizadas pesquisas bibliográficas e documentais. No tocante ao instrumento de coleta, utilizou-se o questionário. Foram realizadas análises indutivas e comparativas, bem como estatística multivariada. De forma geral, destaca-se que a Secretaria de Governança constitui fator de sucesso para a Governança na UFC, porquanto é um lócus que pensa e instrumentaliza a governança nessa instituição. Por sua vez, o tamanho e a diversidade da UFC constituem um fator crítico, pois dificultam a implantação de uma cultura de Governança. Conclui-se que a UFC dispõe de todas as condições para o êxito do processo de implantação da Governança, dado o esforço que a sua gestão empreende nesse sentido. Importa destacar o fato de que o elemento-chave está nas

\footnotetext{
1 Contadora, mestre em Controladoria pela Universidade de São Paulo. Doutora em Educação pela Universidade Federal do Ceará. Coordenadora do Curso de Especialização em Auditoria da Universidade Federal do Ceará, professora do Mestrado Profissional em Administração e Controladoria da Universidade Federal do Ceará. E-mail: rcspinho@ufc.br

2 Mestre em Controladoria pela Universidade Federal do Ceará. Técnica de Controle Externo do Tribunal de Contas do Estado do Ceará. E-mail: fátima_tce@yahoo.com.br
} 
pessoas da Instituição. Essas precisam ser formadas, motivadas e envolvidas para que não se tornem antagonistas do processo, de modo que os agentes se achem corresponsáveis pelo êxito da Governança.

Palavras-Chave: Universidade Federal do Ceará. Governança Pública. Percepção dos Gestores.

\section{ABSTRACT}

This study analyze the implementing the Governance System at the Federal University of Ceará (UFC). The establishment of Governance emanates from new practices that tend to change the focus of management, including in the institutions of the Brazilian Public Administration, turning it back to the interests of users. It is a qualitative-quantitative research, descriptive as to the objectives, through a case study carried out at UFC. Regarding technical procedures, bibliographic and documentary research. As the instrument of collection was used the questionnaire. Inductive, comparative and multivariate statistical analyzes were performed. In general, the Governance Secretariat is a success factor for Governance at UFC, as it is a locus that thinks and instrumentalizes governance at that institution. In turn, the size and diversity of the UFC is a critical factor, as it makes it difficult to implement a governance culture. It is concluded that the UFC has all the conditions for the success of the governance implementation process, given the effort that its management has been making in this sense. The key element, however, is the people, considering that they are the ones who embody the organizational culture, in which Governance is inserted. These need to be trained, motivated and involved so that they do not become antagonists of the process, so that the actors feel co-responsible for the success of this endeavor.

Keywords: Federal University of Ceara. Public Governance. Perception of Managers.

Recebido: 07-08-2020

Aprovado: 07-10-2020

Rev. Controle, Fortaleza, v. 19, n.1, p. 194-235, jan./jun. 2021. 


\section{INTRODUÇÃO}

A realidade socioeconômica, política e tecnológica exige mudanças e transformações no papel do Estado e da Administração Pública. Por conseguinte, as instituições públicas são chamadas a desenvolver uma gestão que procure a garantia e a proteção do interesse público, sobretudo, equilibrando as contas e os recursos disponíveis.

Consoante essa realidade, os gestores e administradores de órgãos do governo devem adotar princípios de Governança pública que objetivem garantir processos de trabalho eficientes, eficazes, econômicos, probos, responsáveis, mormente com equilíbrio de custo-benefício e transparência. Os referidos princípios ajudam a orientar os agentes públicos a resgatar a credibilidade governamental pelo surgimento de novas práticas na gestão da coisa pública (LIMA NETO, 2011).

A importância de se adotar a Governança alcança todas as instituições, inclusive as universidades públicas, visto que estas são organizações de significativo interesse social, das quais se espera boa gestão e resultados que façam avançar o nível educacional do país, ou seja, espera-se dessa criação de valor público. A despeito dessa necessidade, as universidades públicas são instituições com idiossincrasias, pelo que não permitem uma análise linear em relação às demais instituições públicas. Acrescenta-se a isso o momento de crise financeira que vivenciam e a constante elevação dos padrões de excelência, que exigem dos dirigentes a adoção de ações orientadas para a eficiência e a eficácia contemplando, ao mesmo tempo, exigências governamentais e anseios sociais e da comunidade acadêmica.

Posto que a Universidade Federal do Ceará (UFC) é uma instituição relevante tanto em termos locais quanto regionais e nacional, figurando entre as melhores academias do País em razão do bom desempenho nas avaliações e rankings que analisam indicadores de ensino, pesquisa e extensão (UFC, 2018) e dado o seu empenho em consolidar a governança 
no âmbito da gestão, demonstrado por meio das ações adotadas, tornou-se elegível como unidade de pesquisa. Antes mesmo dessas iniciativas, o levantamento do TCU, em 2014, já colocava a UFC em um posicionamento bastante destacado em termos de Governança, alcançando, no Índice de Governança Corporativa Simplificado (IGCS), no quesito liderança 61\% (intermediário), em estratégia 47\% (intermediário), 81\% (avançado) em controle, e de forma geral, um aproveitamento de 56\% (intermediário). Assim ficando 43,9\% acima da média das organizações que participaram do levantamento e 53\% acima das instituições federais de ensino superior. Em termos de Governança de TI, alcançou a 23 ${ }^{\mathrm{a}}$ posição entre 106 instituições de ensino superior (PORTAL UFC, 2017). Recentes dados apontam para o avanço da Governança, como a ascensão do terceiro para o segundo lugar no ranking da transparência nacional que avalia o desempenho das universidades no cumprimento da Lei de Acesso à Informação (PORTAL UFC, 2018).

Não obstante as medidas já adotadas no âmbito da UFC no que diz respeito à governança, todo processo de mudança implica superação de desafios e barreiras, independentemente dos fatores favoráveis, condição essa que ratifica a escolha e a definição do problema. Por conseguinte, este estudo poderá contribuir para a compreensão das dificuldades e das potencialidades das universidades públicas na implantação da governança, servindo de referencial para outras entidades similares e oferecendo subsídios para definição de estratégias. No campo acadêmico, suscita a discussão de modelos de governança adequados às especificidades dessas instituições.

Diversos estudos versam sobre governança pública, todavia a abordagem da governança em instituições de ensino superior foi encontrada apenas nos trabalhos de Couto (2018), que disserta sobre governança multinível na Universidade Federal de Santa Catarina, e de Ntim, Soobaroyen e Broad (2017), tratando de estruturas de governança e incremento de 
disclosure em universidades do Reino Unido. Os referidos trabalhos não abordam questões ligadas ao processo de implantação, pelo que esse estudo vem a preencher essa lacuna, considerando que diversas instituições brasileiras se encontram nesta fase. Sabendo disso, buscou-se responder à seguinte pergunta da pesquisa: Quais são os fatores críticos e de sucesso relativos ao processo de implantação da Governança na Universidade Federal do Ceará (UFC)? Para responder a esta questão, foi estabelecido como objetivo geral analisar a implantação da Governança na Universidade Federal do Ceará.

Governança é um processo, por excelência, alicerçado em pessoas. $\mathrm{Na}$ UFC, estas formam um grande contingente, distribuído em distintos locais, com formação diversa e vocações específicas, gerando realidades e visões de mundo multifacetadas. Estudos como o de Couto (2018) e Ribeiro (2014) apontam as universidades como lócus de conflito de ideias, dada essa diversidade e a própria essência do processo de geração do saber. $\mathrm{O}$ pressuposto da pesquisa, portanto, é o de que as percepções das pessoas envolvidas são distintas, tendo em vista uma forte cultura institucional e a diversidade que caracteriza a UFC, constituindo-se no principal fator crítico do processo de implantação da governança. Entende-se que a existência de diferentes percepções é a situação esperada, mas a ausência dessas diferenças é plausível e ambas ensejam diferentes condutas dos gestores frente à criticidade ou ao sucesso que causam ao processo. Do exposto, definiram-se as seguintes hipóteses: $\mathrm{H}_{0}$ - Há distintas percepções quanto às ações emanadas da gestão da UFC visando ao desenvolvimento da Governança; $\mathrm{H}_{1}$ - Não há diferenças entre as percepções quanto às ações emanadas da gestão da UFC visando ao desenvolvimento da Governança.

No que concerne à metodologia, cumpre dizer que a presente pesquisa realizou um estudo de caso descritivo. Quanto à natureza da investigação, realizou-se uma pesquisa com abordagem quali-quantitativa. Quanto aos procedimentos técnicos, considerando a natureza da investiga- 
ção, foram utilizadas pesquisas bibliográficas e documentais, tendo como instrumento de coleta o questionário. Foram realizadas análises indutivas, comparativas e estatísticas multivariadas.

A estrutura deste trabalho contempla, além desta Introdução, a seção relativa ao referencial teórico que trata dos modelos de Administração Pública e de Governança, bases que sustentam esse trabalho científico. Em seguida, na metodologia, encontram-se os procedimentos metodológicos e o corpus de pesquisa. Na seção intitulada de análise dos resultados, foram realizadas análises indutivas e estatísticas dos dados. Por fim, na última seção, são registradas as conclusões do trabalho.

\section{REFERENCIAL TEÓRICO}

Nessa seção apresentam-se assuntos que, direta ou indiretamente, convergem para compreensão do tema Governança nas instituições públicas.

\subsection{Controle e governança no setor público}

A administração pública é dividida em administração direta e indireta. A administração direta é composta pelos órgãos diretamente ligados aos entes da federação: União, estados, Distrito Federal e municípios. A administração indireta é feita por órgãos descentralizados e autônomos, mas sujeitos ao controle do Estado. A administração pública se desenvolveu por meio de três modelos referentes à organização pública das instituições brasileiras: a administração patrimonialista, burocrata e gerencial (SILVA; PEREIRA; ALCÂNTARA, 2012).

No período patrimonialista, o funcionamento do aparelho do Estado era como se ainda fosse uma extensão do poder do soberano, sendo confundidos o patrimônio público e o privado, segundo assevera Oliveira (2012).

A fase burocrática da gestão pública experimentou como qualidade fundamental a efetividade do controle dos abusos do Estado sobre a 
sociedade. Nesse período, ficou clara a ineficiência e a incapacidade de voltar os serviços públicos para os cidadãos, pois os serviços prestados pelo Estado à sociedade eram muito reduzidos, limitavam-se basicamente a manter a ordem e a administrar a função jurisdicional, além de garantir os contratos e a propriedade (SILVA, 2017).

Assim, tendo cumprido o seu papel no passado, o modelo burocrático tornou-se obsoleto em decorrência do caráter excessivamente formalista e rígido, hierarquizado e pouco comprometido com resultados, ou seja, fazendo dos meios o seu objetivo principal. Sobre as consequências e legados dessa fase, destacam-se os vícios de clientelismo, assistencialismo e corrupção, que caracterizavam um Estado brasileiro em crise institucional. Na realidade, esse problema era mais global que nacional (FONTES FILHO, 2014).

No sentido de mudança, impôs-se o princípio da eficiência na Administração Pública visando a atingir os objetivos das instituições públicas, qual seja, atender de forma efetiva aos cidadãos. Esse movimento de reforma nos países ocidentais foi identificado no Brasil com as bases da corrente internacional de Nova Gestão Pública, ou New Public Management - NPM, movimento que, de certa forma, contribuiu para a criação de elementos voltados para a governança.

As universidades federais, embora pertençam à administração indireta, precisam atender aos requisitos impostos pelos novos paradigmas econômicos vindos da administração pública, muitas vezes em desacordo com seus objetivos educacionais e missão. Isso, tendo em vista as suas especificidades, vem sendo um desafio à gestão universitária, a saber, continuar gerando valor público, mas em moldes muitas vezes conflitantes com a sua cultura, o que pressupõe a necessidade de um significativo ajuste para se adequar aos novos tempos.

Nesse sentido, a governança viabiliza mecanismos, desde o planejamento estratégico até o feedback, que permitem à Administração Pública, incluído as entidades da administração indireta, atingir seus fins de criar valor público, cabendo o monitoramento dessas ações ao controle. 
$2.2 \mathrm{O}$ controle na administração pública brasileira

Controle vem a ser o mecanismo utilizado para verificar se o que foi realizado está de acordo com o que foi planejado ou determinado. Di Pietro (2015, p. 879) define o controle da Administração pública como: "[...] o poder de fiscalização e correção que sobre ela exercem os órgãos dos poderes Judiciário, Legislativo e Executivo, com o objetivo de garantir a conformidade de sua atuação com os princípios que são impostos pelo ordenamento jurídico".

Para Meirelles (2003, p. 697), o "[...] controle, em tema de administração pública, é a faculdade de vigilância, orientação e correção que um Poder, órgão ou autoridade exerce sobre a conduta funcional de outro". O controle da administração pública constitui um poder-dever atribuído por lei aos seus órgãos e entidades. Expressa, como finalidade, a legitimidade dos atos em conformidade com a lei, conduta adequada dos respectivos agentes e defesa dos direitos dos administrados.

Entre os vários tipos de controle da administração pública destacam-se o administrativo, legislativo, jurisdicional e social. O primeiro, conhecido como de autotutela, é um controle de legalidade e de mérito, exercido pelos órgãos de administração de todos os poderes, sobre as próprias atividades, com vistas mantê-las dentro da lei, consoante exigências técnicas e econômicas para atender às necessidades dos serviços (TCU, 2012).

O controle legislativo ou político conta com instrumentos para o exercício do controle político, entre outros, as comissões parlamentares de inquérito (CPIs), as convocações de autoridades para esclarecimentos, os requerimentos de informações e a sustação de atos do Poder Executivo que exorbitem do poder regulamentar ou dos limites de delegação legislativa (ALCÂNTARA, 2012).

O controle jurisdicional é essencialmente um controle de legalidade 
efetuado pelo Poder Judiciário sobre os poderes e órgãos da administração pública, ocorrendo sempre a posteriori. Possui como instrumentos a ação popular, a ação civil pública, entre outros.

Por último, o controle social da sociedade sobre o Estado "é o processo de aprimoramento da democracia deliberativa, mediante o ato de controlar as ações do Estado na esfera pública por meio do exercício efetivo da cidadania" (SILVA; CANÇADO; SANTOS, 2016, p.1), logo o Controle Social decorre da accountability e da transparência, princípios de Governança.

Ribeiro (1997) estabelece dois focos de análise: o primeiro diz respeito ao controle operacional e o segundo ao controle sobre a gestão. Analisando mais especificamente a função controle operacional, pode-se observar que consiste na simples averiguação de saber se todas as atividades ocorreram de acordo com o planejado. Ou seja, a percepção do controle se voltava para a ação, visando ao alcance dos objetivos. Já o controle de gestão se volta para os atos decisórios.

Atualmente, o controle sobre a gestão pública tem ganhado notoriedade, pois a sociedade está dando sinais de grande interesse pelos gastos do governo, cobrando melhor aplicação dos recursos públicos e que os atos dos agentes públicos sejam realizados com maior transparência e responsabilidade. Depreende-se que o controle se movimenta de acordo com o modelo de administração praticado. O Quadro 1 apresenta a forma do controle segundo cada modelo de administração. 
Quadro 1: Características das fases da administração pública

\begin{tabular}{|c|c|}
\hline MODELO & FOCO DO CONTROLE \\
\hline $\begin{array}{l}\text { Administração } \\
\text { Patrimonialista }\end{array}$ & $\begin{array}{l}\text { - Formalista e rígida; } \\
\text { - Vícios de corrupção e nepotismo. }\end{array}$ \\
\hline $\begin{array}{l}\text { Administração } \\
\text { Burocrática }\end{array}$ & $\begin{array}{l}\text { - Composta por administradores profissionais recrutados e treinados; } \\
\text { - Baseada na descentralização das decisões; } \\
\text { - Estrutura piramidal de poder; } \\
\text { - Hierarquia funcional e rotinas rígidas; } \\
\text { - Controle passo a passo dos processos administrativos; } \\
\text { - Formalista, rígida e processual. }\end{array}$ \\
\hline $\begin{array}{l}\text { Administração } \\
\text { Gerencial }\end{array}$ & $\begin{array}{l}\text { - Busca pela eficiência e eficácia na aplicação regular dos recursos públicos } \\
\text { - controle dos resultados; } \\
\text { - Inspirado nas ideias de descentralização e flexibilização administrativa; } \\
\text { - Implementação de políticas organizacionalmente distanciada dos } \\
\text { elaboradores de política; } \\
\text { - Autonomia na gestão com o controle de resultados a posteriori. }\end{array}$ \\
\hline Nova Gestão Pública & $\begin{array}{l}\text { - Foco na liderança empreendedora nas organizações públicas; } \\
\text { - Processo de fortalecimento dos relacionamentos institucionais com a } \\
\text { sociedade; } \\
\text { - Processo de geração de valor público, a partir de capacidades e } \\
\text { relacionamentos institucionais, voltados para o desempenho; } \\
\text { - Combinação integrada de iniciativas voltadas à construção de } \\
\text { agenda estratégica, ao alinhamento da estrutura implementadora e ao } \\
\text { monitoramento e avaliação. }\end{array}$ \\
\hline
\end{tabular}

Fonte: Adaptado de Aragão (1997); Fontes Filho (2014); Martins (2010).

O Quadro 1 evidencia a evolução do controle de acordo com as diretrizes vigentes e o alinhamento com o momento experienciado pelas entidades públicas. Segundo Moreira Neto (2007), as ações públicas sobre quaisquer produtos e serviços fornecidos pelo Estado, antes envoltos na burocracia e centralização, tendem hoje a ceder para uma nova modalidade de ação: mais flexível, dialogada e negociada. Essa nova modalidade se identifica com ações de governança, porque envolve a efetividade e eficiência de uma gestão mais democrática. 
2.3 Da governança à governança pública

As origens do termo Governança não são novas. O conceito de Governança aparece em diversos períodos da história e, inicialmente, apresentava uma identificação com governo. Foi citado pelo poeta inglês, Geoffrey Chaucer, em The Governance of house and lands ${ }^{3}$, no século XIV (CALMON, 2013). No ano de 1516, Tomás Morus, em sua obra A Utopia ou O tratado da melhor forma de governo, já expressava formas de governança (MATOS, DIAS, 2013, p. 23).

Maia e Di Sergio (2017, p.163) reforçam que "a ideia de Governança Corporativa surge basicamente da dissociação entre a propriedade e a gestão das empresas. Na medida em que ambas são separadas, surge o possível desalinhamento dos interesses entre aquele que efetivamente detém posse legal da firma e aquele que a gerencia no dia a dia".

Em 1976, Jensen e Meckling publicaram estudos com base em empresas norte-americanas e britânicas, mencionando o que convencionaram chamar de problema do agente-principal (IBGC, 2018). Esses pesquisadores acreditavam ser pertinente ao indivíduo a tentativa de realização de atividades ou tomada de decisões com base em suas próprias preferências ou anseios, o que, além de gerar divergências entre os gestores e os acionistas ou principais, poderia ocasionar em custos, dentre outros gastos, para acompanhamento das ações dos tomadores de decisões (JENSEN; MECKLING, 1976). Desde então, a Teoria da Agência (Agency Theory) ou Teoria da Representação tem sido a abordagem mais utilizada para discutir a Governança Corporativa (SILVEIRA, 2015).

No Brasil, o significado dado pelo Instituto Brasileiro de Governança Corporativa (IBGC) amplia ainda mais as dimensões conceituais, pois expõe que governança "[...] é o sistema pelo qual as organizações são dirigidas, monitoradas e incentivadas, envolvendo os relacionamentos

3 Em português, tradução nossa: "A Governança da Casa e da Terra". 
entre os proprietários, conselho de administração, diretoria e órgãos de controle" (IBGC, 2009, p.19). O acréscimo feito ao conceito destaca a modernização da gestão pela governança, que deve, democraticamente, ter como partícipes os sujeitos envolvidos.

A discussão sobre Governança Corporativa no Brasil iniciou-se sob a influência do movimento mundial em torno do tema. Constitui-se uma consequência da necessidade de as empresas modernizarem a alta gestão, visando a se tornarem mais atraentes para o mercado, de modo a melhorar a captação de investidores nacionais e estrangeiros. Assim, as empresas passaram a se preocupar com a adoção de uma administração mais transparente e também responsável, o que implica mais investimentos, à semelhança daquilo que prevê a teoria da agência.

Torna-se necessário destacar a importância para o Brasil das contribuições e dos estímulos advindos de organismos multilaterais e instituições privadas, como o Banco Mundial, Organização para a Cooperação e Desenvolvimento Econômico (OCDE), Federação Internacional de Contadores (IFAC), Movimento Brasil Competitivo (MBC), Instituto Brasileiro de Governança Corporativa (IBGC), entre outros. Desses, enfatizamse os dois primeiros.

O Banco Mundial contribuiu, principalmente, para o incentivo da boa governança no contexto mundial nos anos de 1990. Em sentido amplo, a agenda de políticas do Banco Mundial deslocou-se das reformas macroeconômicas strictu sensu para as reformas do Estado e da administração pública, objetivando promover a boa governança e fortalecer a sociedade civil (BORGES, 2003). Ao mesmo tempo, o Banco também enfatiza recorrentemente a necessidade de mensurar os custos sociais do ajuste estrutural e de reduzir a pobreza, conferindo grande prioridade à reestruturação dos serviços sociais com o objetivo de incrementar a equidade e a eficiência, buscando o fortalecimento das instituições. 
A Organização para Coordenação do Desenvolvimento Econômico (OCDE) publicou um documento que desenvolveu orientações sobre as melhores práticas de governança nas empresas públicas (OECD, 2005). Pelo que, ao tratar de governança corporativa em empresas estatais, destacou que estas devem ter como base uma série de princípios/dimensões considerados não prescritivos e que se alicerçam nos direitos dos acionistas, no respeito aos stakeholders, na transparência e na responsabilidade da direção corporativa (MATIAS-PEREIRA, 2010). Essas diretrizes contribuíram para a formulação da governança pública no Brasil.

Embora não seja fácil definir governança pública, pois é um termo com várias interpretações, boa parte do entendimento que se tem atualmente advém do modelo de gestão pública imposto pelo Banco Mundial e outras agências de fomento. As reformas neoliberais resultantes desse modelo levaram à reestruturação do papel do Estado na sociedade, cabendolhe, nesta perspectiva, o de coordenação do conjunto de atores envolvidos visando a superar a ineficiência que lhe é comumente atribuída. Na base de uma gestão pública voltada para mobilizar conhecimentos e potencialidades pela sociedade para melhoria da administração pública, no encolhimento do Estado e na inserção dos países na economia global, encontra-se o que se intitula de boa governança (COZZOLIN; IRVING, 2015).

Couto (2018), por sua vez, ao analisar determinado conjunto de definições de governança pública conclui que há uma ilusão na definição do termo, levando o leitor a crer que há similaridade com o conceito de governança corporativa, contudo, afirma, o setor público é diferenciado dada a complexidade e diversidade que o caracteriza, demandando entendimento particularizado. Depreende-se que a ausência desse entendimento aliada à inserção de diversos segmentos da sociedade no processo decisório e no acompanhamento das ações tem gerado dificuldades na efetiva implantação da governança pública no Brasil.

Embora configure uma expressão com distintos significados, a Governança pública é entendida como "uma forma de governo nova que se 
adota com o objetivo de evitar os efeitos derivados da falta de flexibilidade e de capacidade de adaptação das organizações públicas às mudanças que estão ocorrendo nas sociedades atuais" (MATOS; DIAS, 2013, p. 17-18).

Compreende-se, no arcabouço conceitual, cuidar do envolvimento e compartilhamento de responsabilidades da sociedade com o governo em longo prazo (RODRIGUES, 2014; MARTINS; MARINI, 2010). No mesmo sentido, de acordo com a linha de pensamento de Ronconi (2011), governança pública é aquela que:

Desponta como um importante arranjo institucional para a operacionalização dos princípios democráticos, pois se refere a um tipo de gestão do Estado que favorece e reforça a participação de atores sociais nos processos de decisão e de formulação das políticas públicas; portanto nas instâncias de deliberação do Estado (RONCONI, 2011, p. 21).

A autora destaca na Governança pública a participação dos agentes sociais. A sociedade civil é vista como imprescindível para a consolidação da democracia, pelo fato de existir a participação de variados agentes nos processos de decisão, nas diversas instâncias de deliberação e de decisão do Estado.

Segundo o Tribunal de Contas da União - TCU (2014), também pode ser entendida como um sistema pelo qual os recursos de uma organização são dirigidos, controlados e avaliados. Para Castro, a Governança Pública é entendida com um aspecto mais amplo como:

a força que determina o equilíbrio de poder entre governantes, gestores, servidores e sociedade com a finalidade precípua de fazer prevalecer o interesse público sobre os interesses particulares, com vistas à consecução do bem comum, reduzindo os custos e aumentando o nível de transparência dos governos (CASTRO, 2015, p. 6).

O resultado esperado é o atendimento às demandas, aos interesses e 
às expectativas dos beneficiários, criando valor público. Por conseguinte, gestão para resultados significa alinhar os arranjos de implementação que envolvem intrincados conjuntos de políticas, programas, projetos e distintas organizações para alcançá-los, além de envolver a construção de mecanismos de monitoramento e de avaliação que promovam aprendizado, transparência e responsabilização (MARTINS; MARINI, 2010).

Já a ideia de Governança por resultados está ligada à necessidade de transformar objetivos estratégicos em resultados, envolvendo todos os funcionários, que devem ter uma percepção global de todas as tarefas e processos que a entidade adota como gestão. Todavia, para se realizar uma Governança por resultados no setor público, inicialmente, devem ser estabelecidos os resultados desejados (RODRIGUES, 2015).

A Governança por resultados implanta uma sistemática de mensuração para o cumprimento dos objetivos da gestão, a qual permite analisar, interpretar, comunicar e revisar a estratégia que é a de gerar valor público. Isso quer dizer que o serviço público prestado deve ser de tal forma eficiente e efetivo que traga resultados que impactam a sociedade, contribuindo com alguma mudança.

Entre as principais ações para a implantação da Governança pública em instituições brasileiras está a Instrução Normativa conjunta $\mathrm{n}^{\mathrm{o}} 1$ de 10 de maio de 2016, do Ministério da Transparência e Controladoria Geral da União (CGU) e do Ministério do Planejamento, Orçamento e Gestão (MPOG). Constitui um conjunto de medidas para a sistematização de práticas relacionadas à gestão de riscos, aos controles internos e à Governança do setor público (BRASIL, 2016). Também não pode deixar de ser mencionado o Decreto 9.203/17 que estabeleceu a Política de Governança no âmbito federal e criou o Comitê interministerial de Governança.

Nesse contexto, se notabiliza a articulação entre os atores do setor público, mas também a necessidade de que os resultados esperados estejam inseridos em programas e projetos da Administração Pública a fim de 
que a governança seja efetiva. No que concerne às universidades públicas, as grandes especificidades que a caracterizam não podem ser negligenciadas, haja vista serem muito complexas e o fato de haver dificuldades em conciliar interesses internos e demandas externas como, por exemplo, as emanadas dos órgãos de controle.

Couto (2018) ressalta que as decisões podem ser influenciadas por um ou mais grupos de poder, a saber: governo, oligarquia acadêmica e mercado, cujos interesses podem estar em direções opostas. No centro deste dilema está o fato de que o conhecimento, que é o produto da Universidade, não apresenta resultados imediatos e quantificáveis; assim como a autonomia universitária que não se coaduna às estruturas rígidas de controle.

\subsection{Estudos anteriores}

Corroborando o entendimento que vem sendo engendrado até o momento, estudos publicados sobre Governança do setor público e universidades públicas já vêm sendo desenvolvidos. Ntim, Soobaroyen e Broad (2014) investigaram a extensão das divulgações voluntárias nos relatórios anuais das instituições de ensino superior (IES) do Reino Unido e examinaram se as estruturas de governança interna influenciaram a divulgação no período após uma grande reforma e restrições de financiamento. Os autores descobriram que a interação entre as características da equipe de executivos e as variáveis de governo aumenta o nível de divulgações voluntárias, fornecendo assim suporte para a relevância continuada da liderança "compartilhada" no sentido de melhorar a responsabilidade e transparência nas IES.

Registra-se também a realização de cinco estudos de caso que resultaram no Relatório de Avaliação sobre a Governança dos recursos hídricos (OECD, 2015). Tal estudo indicou diferentes níveis de Governança e a dificuldade na coordenação da gestão entre esses comitês quanto ao processo de gestão de políticas públicas sobre água. 
A pesquisa de Rodrigues (2015), realizada em uma empresa pública de tecnologia da informação, destacou os estudos da gestão por objetivos e da gestão para resultados. O ponto forte foi a construção de um modelo de avaliação em uma empresa, cujo resultado veio a refletir na percepção dos funcionários e gestores sobre o desempenho e respectivos determinantes para uma governança por resultados.

Já Cozzolino e Irving (2015) trataram da concepção de governança em sua aplicação à gestão pública, tendo os conselhos como foco central de reflexão, e concluíram que a concepção democrático-participativa de governança pareceu ser aquela que melhor contempla o compromisso com as dimensões de controle social e accountability envolvidas nos processos de gestão pública. Oliveira e Pisa (2015) se propuseram a desenvolver um índice de medição da governança pública e a fazer isso a partir do ponto de vista de seus princípios, bem como apresentá-lo como um instrumento de autoavaliação e planejamento para o Estado e de controle social para os cidadãos, empreitada que cumpriram com êxito.

Travaglia e César (2016) descrevem a pesquisa realizada pelos Tribunais de Contas brasileiros sobre a importância do controle interno como instrumento de Governança pública, na qual foi obtido um diagnóstico em que, entre as 7.770 organizações públicas pesquisadas, mais da metade apresentava um baixo nível de adesão às práticas de gestão de risco e de controles internos, que são ferramentas de Governança. Barbosa (2017), ao investigar a aderência aos princípios de Governança no setor público propostos no modelo do PSC/IFAC, indicou que o estado de Goiás ainda precisava avançar na Governança pública, nos setores de TI, de aquisições e de gestão de pessoas.

Couto (2018) analisou os mecanismos de governança na Universidade Federal de Santa Catarina à luz do modelo multilevel governance evidenciando, a partir dos resultados obtidos, a existência de instrumentos que se referem às práticas da multilevel governance. Concluíram que esses instrumentos se encontravam em estágio inicial, uma vez que, apesar da 
reconhecida importância da governança na gestão da UFSC, a discussão sobre sua evolução ainda é limitada e suas práticas ainda não estão efetivamente internalizadas pela organização.

Referidos estudos confirmam que a governança pública é um campo do saber em construção, envolto em um contexto de mudança de paradigmas, resultante da necessidade que o Estado tem de se adequar ao novo papel. A governança auxilia não só o governo a se ajustar a dinâmica estabelecida, mas também a sociedade e as instituições. As universidades públicas não são exceção a essa regra, pelo que demandam que a governança seja vista na perspectiva da sua diversidade e complexidade.

\section{METODOLOGIA}

Esse, prioritariamente, é um estudo de caso com objetivo descritivo, por meio do qual se investigou um fenômeno contemporâneo dentro do contexto da vida real, com vistas a conhecer e descrever o fenômeno da percepção dos gestores da Universidade Federal do Ceará (UFC) a respeito da Governança.

Quanto à natureza, realizou-se uma pesquisa de métodos mistos, pois abrangeu tanto a abordagem qualitativa quanto a quantitativa. Quanto aos procedimentos técnicos, considerando a natureza da investigação que se desenvolveu, foram utilizadas pesquisas bibliográficas, documentais e aplicação de questionário.

O locus preponderante, no caso investigado, foi o espaço físico e virtual da Universidade Federal do Ceará (UFC), dada a sua importância para o desenvolvimento econômico, social e científico do estado do Ceará, bem como a constatação do fato de essa instituição ser uma das poucas que possuem uma estrutura organizacional específica para a Governança. Criada em 1954, a UFC oferta 119 cursos de graduação (110 presenciais e 9 virtuais), atuando nos eixos de ensino, pesquisa e extensão, e 94 de 
pós-graduação (41 mestrados acadêmicos, 7 mestrados profissionais e 36 doutorados). Conta com cerca de 700 ações de extensão, beneficiando milhares de pessoas em todo o estado (PORTAL UFC, 2017).

Para a coleta de dados utilizou-se três técnicas, a saber, coleta de documentação, abrangendo os seguintes documentos: IN Conjunta MP/ CGU no 01/2016, Decreto No 9.203/2017, Portaria No 4.117/2017 e Resoluções nos 1 e 34 de 2017, da UFC; registro em arquivos, Atas das Câmaras do Comitê de Governança, Plano de Desenvolvimento Institucional (PDI) e o Plano de Governança; e, por último, aplicação de questionário estruturado de forma a garantir o controle da quantidade de vieses abordados, possuindo 15 questões fechadas e sendo aplicado aos 31 gestores que fazem parte do Comitê de Governança da UFC, a saber: diretores das unidades acadêmicas (gestores das atividades-fim); pró-reitores e dirigentes de órgãos suplementares e de assessoria ao reitor (gestores das atividades-meio).

As perguntas foram construídas a partir de variáveis de análise identificadas nos objetivos específicos e estruturadas de acordo com a escala de Likert de cinco pontos, dividindo-se em "discordo totalmente, discordo parcialmente, nem concordo nem discordo, concordo parcialmente e concordo totalmente". As quinze questões foram agrupadas em três fatores: o primeiro fator agrupou perguntas sobre Melhorias trazidas pela implantação da Governança; o segundo sobre Estratégias de divulgação/ implantação do processo de Governança; e o terceiro sobre Envolvimento dos agentes com a Governança.

Quando do tratamento e análise dos resultados do questionário aplicado foram utilizados os métodos de análise multivariada, como cálculo do Alpha de Cronbach e Análise Fatorial Exploratória, buscando identificar a confiabilidade do mesmo, bem como a presença de agrupamentos de questões relacionadas a um mesmo assunto medido (Fatores), para então serem comparados com as informações de perfil levantadas. 
Em seguida, cada Fator foi comparado com as informações do perfil do respondente, a fim de se identificar possíveis diferenças significativas de respostas. Para tanto, utilizou-se uma abordagem não-paramétrica, para os Fatores que não seguiram distribuição normal, e testes paramétricos em dados cuja hipótese de normalidade foi aceita, atestada pelo teste de Shapiro-Wilk.

Com isso, foram utilizados, para comparação estatística, os testes de Wicoxon-Mann-Whitney e de Kruscal-Wallis, para os dados não normais, e o teste t de Student de amostras não pareadas e One-Way ANOVA, para dados normalmente distribuídos. Para toda conclusão dos testes, foi adotado um nível de significância estatística de 5\%, que se traduz como a probabilidade de cometer um erro do Tipo I, ou seja, rejeitar indevidamente uma hipótese verdadeira. Os dados da pesquisa foram analisados utilizando o software SPSS 20, JMP 13 for SAS e R 3.4.1.

\section{RESULTADOS}

Os resultados da pesquisa foram evidenciados em três subseções: análise documental, análise e comparações estatísticas.

\subsection{Análise documental}

A análise do PDI UFC 2018-2022 demonstrou que a governança assumiu um papel estratégico e fundamental, tendo em vista que este documento: (i) traz uma apresentação e metodologia com a participação de toda a comunidade, pois previu assembleias com estudantes, professores e técnico-administrativos, essa ampla participação tem relação com o princípio da equidade e pressupõe considerar a contribuição de todos os agentes para a gestão; (ii) destaca uma estrutura organizacional propícia à Governança, pois o Comitê e a Secretaria de Governança assessoram 
a Administração Superior da UFC; (iii) define como princípio norteador a Governança; (iv) indica em sua visão as práticas de Governança como referencial para atingir os fins; (v) estabelece um objetivo estratégico específico que contempla a Governança; e (vi) torna transparente todo o processo de desenvolvimentos institucional, pois garante o acesso livre por meio do sítio eletrônico ao processo e ao texto do PDI. Nesses termos, o PDI aponta para um prognóstico de êxito na implantação da Governança na UFC entre os exercícios de 2018 e 2022.

Quanto à estrutura organizacional da Governança na UFC, prevista por meio da Resolução $n^{\circ} 1$, de 20 de janeiro de 2017, Consuni/UFC, observa-se que a Secretaria de Governança foi incluída na categoria dos Órgãos Suplementares, indicando uma preocupação com a efetiva implantação da Governança, haja vista que está vinculada à estrutura máxima de gestão da UFC, a Reitoria.

Quanto ao Comitê de Governança, criado pela Resolução $\mathrm{n}^{\circ}$ 34/2017, órgão colegiado com caráter deliberativo de apoio ao Reitor, o qual conta com o apoio da Secretaria de Governança, tem por objetivo elaborar e aprovar, a partir do PDI, a proposta de execução de uma política de gestão administrativa com o envolvimento de todos os órgãos integrantes da estrutura organizacional da UFC, na capital e no interior do estado. As reuniões das Câmaras do Comitê de Governança têm suas atas divulgadas no sítio eletrônico da UFC. Com isso, assegura-se a obediência ao princípio da transparência, posto que são disponibilizadas as informações e decisões das Câmaras supracitadas. Essas ações representam aspectos positivos do processo.

Ademais é perceptível que, ao tratar das competências desse Comitê, a resolução supracitada deixa clara a necessidade do estabelecimento de um ambiente de gestão de riscos que respeite os valores, interesses e expectativas da organização e dos agentes que a compõem. Entende-se que a UFC adota o modelo de Governança por resultados, pois visa sobre- 
modo assegurar resultados satisfatórios para os cidadãos. Para esse fim, foi definida a política da instituição, conforme é abordado a seguir.

As diretrizes estabelecidas na Política de Governança da UFC, por meio da Portaria $n^{\circ} 4.117 / 2017$, foram instituídas com o objetivo de implantar uma gestão moderna, transparente e participativa, capaz de assegurar o cumprimento eficaz das ações previstas no PDI. Essa afirmação se justifica especialmente devido ao artigo $3^{\circ}$, I, que visa à consecução de uma efetiva gestão por resultados, conforme o cumprimento de metas estabelecidas no PDI.

Também, destaca-se que a Portaria n ${ }^{\circ} 4.117 / 2017$, no artigo $2^{\circ}$, define princípios gerais de política de Governança compatíveis com os princípios dispostos na IN MP/CGU no 01/16. No Capítulo IV, da Governança, da IN MP/CGU $n^{\circ} 01 / 16$, foram indicados seis princípios que devem ser seguidos pelos órgãos e entidades do Poder Executivo Federal, são esses: liderança, integridade, responsabilidade, compromisso, transparência e accountability. A Portaria Reitoria/UFC $\mathrm{n}^{\circ} 4.117 / 17$ prevê mecanismos integrados de efetivação desses mesmos princípios.

Na verdade, a Política de Governança da UFC está alicerçada em cinco princípios gerais, quais sejam, o de desenvolvimento da liderança; integridade; compromisso ético; transparência e responsabilidade dos agentes e da obrigação de prestação de contas. Afirma-se que há conformidade com os princípios estabelecidos na referida instrução normativa, porque o quinto princípio engloba os de responsabilidade e de accountability.

Quanto ao Plano de Ações Estratégicas da Secretaria de Governança, com base nos objetivos estratégicos, destaca-se que as ações a serem realizadas por essa unidade se concentram em doze ações para o Eixo Gestão e duas para o Eixo Ensino, o que indica numericamente maior ênfase nas ações do Eixo Gestão. Nota-se, neste ponto, uma distorção, pois na elaboração do PDI não parece haver associação da Governança ao Ensino, Pesquisa e Extensão. 
Acredita-se que a continuidade da campanha de difusão de uma cultura pró-Governança pode melhorar a compreensão e levar ao entendimento que Governança se aplica a todos os âmbitos da Universidade e permeia o dia a dia de todos os gestores, nas áreas fim e meio. Foi possível observar que para o cumprimento do objetivo de consolidar o modelo de Governança muitas ações dependeriam de outras unidades, pois extrapolavam a estrutura da Secretaria de Governança.

\subsection{Análise estatística descritiva}

$\mathrm{O}$ instrumento de pesquisa foi respondido por 22 das 31 pessoas que o receberam, o que representa uma taxa de resposta de $71 \%$.

Quanto ao perfil social dos gestores à faixa etária, identificou-se a predominância de gestores com idade acima de 51 anos, o que indica um perfil mais maduro desse público. A participação das mulheres entre os gestores que compõem o Comitê de Governança da UFC é reduzida, uma vez que $68 \%$ são do gênero masculino e apenas $32 \%$ são do gênero feminino.

Ainda que a amostra seja predominantemente formada por indivíduos que possuem formação na área de exatas (53\%), observou-se uma grande diversidade na formação acadêmica dos entrevistados. Também foi possível observar que os entrevistados têm um elevado nível de instrução, uma vez que $91 \%$ possuem pelo menos mestrado e $82 \%$ possuem doutorado ou pós-doutorado.

No que se refere às áreas de atuação, metade dos entrevistados se dedica concomitantemente às atividades administrativas e acadêmicas. Como se trata de gestores que são professores é comum que a maioria desses profissionais acumule a atividade acadêmica e de gestão.

Em relação ao tempo de instituição, a maioria dos entrevistados (73\%) trabalha há mais de 16 anos na Universidade. Ademais, destaca-se que o perfil de gestores da UFC é o de um profissional com possibilidade 
de ter significativo conhecimento da Instituição, dado o tempo de trabalho.

De forma similar ao verificado com relação ao tempo de instituição, todos os gestores exercem a atual função há pelo menos 3 anos. Porém, apenas $9 \%$ possuem um tempo na função superior a 16 anos, enquanto $50 \%$ a exercem por um período de 6 a 10 anos.

A Tabela 1 demonstra as frequências relativas dos itens para todos os respondentes. Nota-se certa discrepância entre o que se coletou na análise documental e o que pensam esses gestores.

Tabela 1: Frequência relativa dos itens por questão

\begin{tabular}{|c|c|c|c|c|c|}
\hline \multirow[b]{2}{*}{ Questão } & \multicolumn{5}{|c|}{ Frequência Relativa } \\
\hline & $\begin{array}{l}\text { Discordo } \\
\text { Totalmente }\end{array}$ & $\begin{array}{c}\text { Discordo } \\
\text { Parcialmente }\end{array}$ & Neutro & $\begin{array}{c}\text { Concordo } \\
\text { Parcialmente }\end{array}$ & $\begin{array}{l}\text { Concordo } \\
\text { Totalmente }\end{array}$ \\
\hline $\begin{array}{l}1 \text { Ações estratégicas } \\
\text { estão alinhadas }\end{array}$ & $23 \%$ & $41 \%$ & $27 \%$ & $5 \%$ & $5 \%$ \\
\hline $\begin{array}{l}2 \text { Houve sensibilização } \\
\text { da comunidade }\end{array}$ & $5 \%$ & $45 \%$ & $18 \%$ & $32 \%$ & $0 \%$ \\
\hline $\begin{array}{l}3 \text { Secretaria e Comitê } \\
\text { são importantes }\end{array}$ & $41 \%$ & $32 \%$ & $14 \%$ & $14 \%$ & $0 \%$ \\
\hline $\begin{array}{l}4 \text { Ações de formação } \\
\text { atendem necessidade }\end{array}$ & $5 \%$ & $36 \%$ & $45 \%$ & $14 \%$ & $0 \%$ \\
\hline $\begin{array}{c}5 \text { Conjunto de normativos } \\
\text { favorece }\end{array}$ & $9 \%$ & $59 \%$ & $14 \%$ & $18 \%$ & $0 \%$ \\
\hline $\begin{array}{c}6 \text { Dirigentes compartilham } \\
\text { com liderados }\end{array}$ & $9 \%$ & $41 \%$ & $27 \%$ & $23 \%$ & $0 \%$ \\
\hline 7 Divulgação é satisfatória & $9 \%$ & $36 \%$ & $27 \%$ & $27 \%$ & $0 \%$ \\
\hline $\begin{array}{l}8 \text { Há envolvimento } \\
\text { dos segmentos }\end{array}$ & $5 \%$ & $27 \%$ & $36 \%$ & $32 \%$ & $0 \%$ \\
\hline $\begin{array}{l}9 \text { Alunos e servidores } \\
\text { comprometidos }\end{array}$ & $5 \%$ & $5 \%$ & $45 \%$ & $45 \%$ & $0 \%$ \\
\hline $\begin{array}{l}10 \text { Há boa compreensão } \\
\text { dos servidores }\end{array}$ & $0 \%$ & $14 \%$ & $41 \%$ & $45 \%$ & $0 \%$ \\
\hline $\begin{array}{l}11 \text { Governança contribuirá } \\
\text { para transparência }\end{array}$ & $36 \%$ & $36 \%$ & $9 \%$ & $0 \%$ & $14 \%$ \\
\hline $\begin{array}{l}12 \text { Governança é } \\
\text { necessidade }\end{array}$ & $9 \%$ & $36 \%$ & $27 \%$ & $23 \%$ & $5 \%$ \\
\hline
\end{tabular}


Tabela 1: Frequência relativa dos itens por questão (continuação)

\begin{tabular}{c|c|c|c|c|c}
\hline $\begin{array}{c}13 \text { Desenvolver cultura } \\
\text { de governança contribui }\end{array}$ & $55 \%$ & $27 \%$ & $9 \%$ & $5 \%$ & $5 \%$ \\
\hline $\begin{array}{c}14 \text { Governança traz melho- } \\
\text { rias para usuários }\end{array}$ & $50 \%$ & $32 \%$ & $9 \%$ & $0 \%$ & $9 \%$ \\
\hline $\begin{array}{c}15 \text { O processo está } \\
\text { avançando }\end{array}$ & $18 \%$ & $45 \%$ & $27 \%$ & $9 \%$ & $0 \%$ \\
\hline
\end{tabular}

Fonte: Elaborada pelas autoras (2018).

A Tabela 2 demonstra as frequências absolutas e relativas dos itens e as respectivas análises descritivas para o grupo de gestores das atividades-fim e o grupo de gestores das atividades-meio.

Tabela 2: Frequências absoluta e relativa das respostas dos gestores das atividades-fim e o das atividades-meio

\begin{tabular}{c|c|c|c|c|c|c}
\hline \multirow{2}{*}{ Item } & \multicolumn{2}{|c|}{ Gestores atividades-fim } & \multicolumn{2}{c|}{ Gestores atividades-meio } & \multicolumn{2}{|c}{ Total } \\
\cline { 2 - 7 } & $\begin{array}{c}\text { Frequência } \\
\text { Absoluta }\end{array}$ & $\begin{array}{c}\text { Frequência } \\
\text { Relativa }\end{array}$ & $\begin{array}{c}\text { Frequência } \\
\text { Absoluta }\end{array}$ & $\begin{array}{c}\text { Frequência } \\
\text { Relativa }\end{array}$ & $\begin{array}{c}\text { Frequência } \\
\text { Absoluta }\end{array}$ & $\begin{array}{c}\text { Frequência } \\
\text { Relativa }\end{array}$ \\
\hline $\begin{array}{c}\text { Discordo } \\
\text { Totalmente }\end{array}$ & 26 & $14 \%$ & 35 & $23 \%$ & 61 & $19 \%$ \\
\hline $\begin{array}{c}\text { Discordo } \\
\text { Parcialmente }\end{array}$ & 74 & $41 \%$ & 39 & $26 \%$ & 113 & $34 \%$ \\
\hline Neutro & 40 & $22 \%$ & 43 & $29 \%$ & 83 & $25 \%$ \\
\hline $\begin{array}{c}\text { Concordo } \\
\text { Parcialmente }\end{array}$ & 36 & $20 \%$ & 28 & $19 \%$ & 64 & $19 \%$ \\
\hline $\begin{array}{c}\text { Concordo } \\
\text { Totalmente }\end{array}$ & 4 & $2 \%$ & 4 & $3 \%$ & 8 & $2 \%$ \\
\hline Total & $\mathbf{1 8 0}$ & $\mathbf{1 0 0 \%}$ & $\mathbf{1 4 9}$ & $\mathbf{1 0 0 \%}$ & $\mathbf{3 2 9}$ & $\mathbf{1 0 0 \%}$ \\
\hline
\end{tabular}

Fonte: Elaborada pelas autoras (2018).

Ao comparar os dados referentes às frequências de respostas em cada grupo, observa-se a ausência de diferenças significativas, exceto pelo item "discordo parcialmente" que apresentou a maior variação, tendo uma frequência relativa de $34 \%$ para toda a amostra, $41 \%$ para o grupo de atividades-fim e $26 \%$ para o grupo atividades-meio.

\subsection{Comparações estatísticas}


A Tabela 3 mostra a presença de 3 fatores (autovalores $>1$ ) dentre as 15 questões analisadas que são capazes de explicar $77,57 \%$ de toda a variabilidade dos dados. Para dar continuidade as análises, serão extraídos os fatores considerando a rotação pelo método Varimax.

Tabela 3: Fatores e variância explicada

\begin{tabular}{c|c|c|c}
\hline \multirow{2}{*}{ Componentes } & \multicolumn{3}{|c}{ Autovalores } \\
\cline { 2 - 4 } & Autovalores & $\begin{array}{c}\text { \% da Variância } \\
\text { explicada }\end{array}$ & Variância acumulada \\
\hline 1 & 7,14 & 47,59 & 47,59 \\
\hline 2 & 3,33 & 22,21 & 69,81 \\
\hline 3 & 1,16 & 7,77 & 77,57 \\
\hline 4 & 0,91 & 6,07 & 83,64 \\
\hline 5 & 0,55 & 3,64 & 87,28 \\
\hline 6 & 0,53 & 3,53 & 90,81 \\
\hline 7 & 0,39 & 2,61 & 93,43 \\
\hline 8 & 0,33 & 2,20 & 95,63 \\
\hline 9 & 0,23 & 1,54 & 97,17 \\
\hline 10 & 0,17 & 1,16 & 98,33 \\
\hline 11 & 0,13 & 0,84 & 99,17 \\
\hline 12 & 0,06 & 0,40 & 99,56 \\
\hline 13 & 0,05 & 0,31 & 99,87 \\
\hline 14 & 0,02 & 0,11 & 99,98 \\
\hline 15 & 0,00 & 0,02 & 100,00 \\
\hline
\end{tabular}

Fonte: Elaborada pelas autoras (2018).

George e Mallery (2003) qualificam a consistência interna de um questionário segundo o valor do coeficiente alfa de Cronbach. A interpretação do coeficiente alfa de Cronbach é aparentemente intuitiva porque, na maior parte das vezes, os valores variam entre 0 e 1 . Entende-se que a consistência interna de um questionário é tanto maior quanto mais perto de 1 estiver o valor da estatística. O teste Alpha de Cronbach, que testa a confiabilidade do questionário, alcançou valor de $91,2 \%$, indicando que o 
instrumento utilizado na coleta das informações é excelente.

Devido ao desconhecimento dos fatores envolvidos no questionário aplicado, há a necessidade de se verificar a existência de variáveis latentes (ou Fatores) dentro do instrumental. Para isso, foram empregados métodos de análise multivariada.

A Tabela 3 mostra a presença de 3 fatores (autovalores $>1$ ), dentre as 15 questões analisadas, que são capazes de explicar $77,57 \%$ de toda a variabilidade dos dados. Para dar continuidade às análises, foram extraídos os fatores considerando a rotação pelo método.

A Tabela 4 mostra os fatores retirados por meio de rotação do tipo Varimax, o qual relaciona melhor a distribuição das questões com os fatores que as representam. É importante notar que as questões 1, 5, 8 e 15 estão relacionadas com mais de um fator, portanto, devido à falta de clareza de sua representação, optou-se por retirá-las da análise.

Tabela 4: Cargas fatoriais dos Fatores rotacionados pelo Método Varimax

\begin{tabular}{c|c|c|c}
\hline \multirow{2}{*}{ Questões } & \multicolumn{3}{|c}{ Fatores* } \\
\hline & 0,637 & $\mathbf{2}$ & $\mathbf{3}$ \\
\hline Q1 & 0,585 & 0,599 & \\
\hline Q2 & 0,826 & & \\
\hline Q3 & & & \\
\hline Q4 & 0,71 & 0,876 & \\
\hline Q5 & & 0,537 & 0,662 \\
\hline Q6 & & 0,597 & 0,924 \\
\hline Q7 & & 0,677 & 0,836 \\
\hline Q8 & & 0,589 & \\
\hline Q9 & & & \\
\hline Q10 & 0,874 & & 0,534 \\
\hline Q11 & 0,781 & & \\
\hline Q12 & 0,917 & & \\
\hline Q13 & 0,889 & 0,505 & \\
\hline Q14 & 0,558 & & \\
\hline Q15 & & & \\
\hline
\end{tabular}

Fonte: Elaborada pelas autoras (2018). 
As comparações estatísticas apresentadas a seguir são resultantes da análise dos três fatores, entre os quais foram divididas as 15 questões propostas, e cujos resultados foram representados pela média aritmética das respostas das referidas questões.

Fator 1: Melhorias trazidas pela implantação da Governança Questões 2, 3, 11, 12, 13 e 14

Fator 2: Estratégias de divulgação/implantação do processo de Governança-Questões 4, 6 e 7.

Fator 3: Envolvimento dos agentes com a Governança-Questões 9 e 10.

Os fatores encontrados serão utilizados em substituição às questões para que se teste a hipótese de que há diferenças significativas entre os níveis de respostas dos gestores, agrupados em faixa etária, gênero, nível de escolaridade, área de atuação, tempo de trabalho na instituição e tempo de trabalho na função exercida.

Aplicou-se o Teste de normalidade de Shapiro-Wilk com o objetivo de obter uma estatística de teste para avaliar se a amostra tem distribuição Normal a um nível de significância $(\alpha)$, normalmente 0,05 . Verificou-se que os dados relativos aos Fatores 1 e 3 possuem distribuição normal. Embora o teste não permita a mesma conclusão para o Fator 2, é possível assumir normalidade nessa distribuição, desde que se opte por uma abordagem não paramétrica de comparação para se garantir maior segurança nas inferências que serão feitas.

As Tabelas 4, 5 e 6 expõem os resultados dos testes que verificam a relação entre as variáveis do perfil dos respondentes com as respostas dadas às questões vinculadas a cada um dos três fatores, Teste de Wilcoxon-MannWhitney, Teste de Kruskal-Wallis, Teste t de Student e One-Way ANOVA. 
Tabela 5: Teste de Wilcoxon-Mann-Whitney e Kruskal-Wallis aplicados ao Fator 1

\begin{tabular}{c|c|c|c|c}
\hline Fator & Grupo & Níveis & Estatística & p-valor \\
\hline \multirow{4}{*}{ Fator 1 } & Gênero $^{1}$ & 2 & 33,5 & 0,1906 \\
\cline { 2 - 5 } & Faixa Etária $^{1}$ & 2 & 66,5 & 0,4933 \\
\cline { 2 - 5 } & Nível de escolaridade $^{2}$ & 3 & 0,054 & 0,9735 \\
\cline { 2 - 5 } & Área de atuação $^{1}$ & 2 & 45,5 & 0,5684 \\
\cline { 2 - 5 } & Tempo de instituição $^{1}$ & 2 & 34,5 & 0,3361 \\
\cline { 2 - 5 } & Tempo de função $^{1}$ & 2 & 63,5 & 0,8426 \\
\hline
\end{tabular}

Fonte: Elaborada pelas autoras (2018).

${ }^{1}$ Teste de Wilcoxon-Mann-Whitney ao nível de 5\%

${ }^{2}$ Teste de Kruskal-Wallis ao nível de 5\%

Os testes demonstram não haver qualquer relação estre as variáveis de perfil dos respondentes com a respostas dadas às questões voltadas ao Fator 1, pois indicam p-valor maior que 0,05 .

Tabela 6: Teste t de Student para amostras independentes e One Way ANOVA aplicados ao Fator 2

\begin{tabular}{c|c|c|c|c}
\hline Fator & Grupo & Níveis & Estatística & p-valor \\
\hline \multirow{4}{*}{ Fator 2 } & Gênero $^{1}$ & 2 & 61,5 & 0,5454 \\
\cline { 2 - 5 } & Faixa Etária $^{1}$ & 2 & 32,5 & 0,1132 \\
\cline { 2 - 5 } & Nível de escolaridade $^{2}$ & 3 & 0,091 & 0,9557 \\
\cline { 2 - 5 } & Área de atuação $^{1}$ & 2 & 51 & 0,8577 \\
\cline { 2 - 5 } & Tempo de instituição $^{1}$ & 2 & 62,5 & 0,2976 \\
\cline { 2 - 5 } & Tempo de função $^{1}$ & 2 & 62,5 & 0,8941 \\
\hline
\end{tabular}

Fonte: Elaborada pelas autoras (2018).

${ }^{1}$ Teste t de Student para amostras independentes ao nível de 5\%

${ }^{2}$ Teste One-Way ANOVA ao nível de 5\%

Os testes demonstrados na Tabela 6 se mostraram não significativos, uma vez que todos os p-valores foram maiores que o valor de significância de 5\%. Logo, conclui-se que o perfil dos respondentes não influenciou nas respostas dadas às questões que medem o Fator 2. 
Tabela 7: Teste de Wilcoxon-Mann-Whitney e Kruskal-Wallis aplicados ao Fator 3

\begin{tabular}{c|c|c|c|c}
\hline Fator & Grupo & Níveis & Estatística & p-valor \\
\hline \multirow{4}{*}{ Fator } & Gênero $^{1}$ & 2 & 66,5 & 0,3199 \\
\cline { 2 - 5 } & Faixa Etária $^{1}$ & 2 & 39 & 0,2391 \\
\cline { 2 - 5 } & Nível de escolaridade $^{2}$ & 3 & 0,999 & 0,6068 \\
\cline { 2 - 5 } & Área de atuação $^{1}$ & 2 & 0,625 & 0,5535 \\
\cline { 2 - 5 } & Tempo de instituição $^{1}$ & 2 & 52 & 0,7874 \\
\cline { 2 - 5 } & Tempo de função $^{1}$ & 2 & 57 & 0,8632 \\
\hline
\end{tabular}

Fonte: Elaborada pelas autoras (2018).

${ }^{1}$ Teste de Wilcoxon-Mann-Whitney ao nível de 5\%

${ }^{2}$ Teste de Kruskal-Wallis ao nível de 5\%

Ao se observar os resultados dos testes, relativamente ao Fator 3, todos se mostraram não significativos ao nível de 5\%. Pode-se também concluir, ao nível confiança de $95 \%$, que o perfil dos participantes da pesquisa não teve qualquer influência nas respostas relativas ao Fator 3.

Tabela 8: Teste de comparação entre as respostas separadas por profissionais de atividades Fim e Meio

\begin{tabular}{c|c|c|c|c}
\hline Fator comparado & Grupo & Níveis & Estatística & p-valor \\
\hline \multirow{3}{*}{ Atividade } & ${\text { Fator } 1^{1}}^{*}$ & 2 & 43 & 0,2748 \\
\cline { 2 - 5 } & Fator $2^{2}$ & 2 & 1,22 & 0,2382 \\
\cline { 2 - 5 } & ${\text { Fator } 3^{1}}^{*}$ & 2 & 70,5 & 0,4907 \\
\hline
\end{tabular}

Fonte: Elaborada pelas autoras (2018).

${ }^{1}$ Teste de Wilcoxon-Mann-Whitney ao nível de 5\%

${ }^{2}$ Teste de $t$ de Student para amostras independentes ao nível de 5\%

Ao analisar as respostas dos profissionais, independente das outras características, separadas apenas por tipo de atividades desenvolvidas no órgão (fim ou meio), verificou-se que essa separação não é capaz de diferenciar os resultados. Ao nível de 5\%, portanto, conclui-se que os gestores lotados em atividades fim ou meio não expressaram níveis de respostas médias diferentes.

Com esteio nos resultados acima expostos e considerando que os testes foram não significativos, pode-se afirmar que a pesquisa aplicada 
não recebeu qualquer influência ou vieses relativos a gênero, idade do participante, sua área de atuação, tempos de atuação ou tipo de atividade desenvolvida. Logo, a hipótese $\mathrm{H} 0$ foi rejeitada, significando dizer que não há distintas percepções entre os gestores. A peculiaridade da constatação é que a similaridade da percepção é no sentido de ignorar todas as ações que vêm sendo desenvolvidas, sendo os respondentes aqueles que integram o Comitê de Governança.

Realizando outra análise, com base numa média ponderada de cada Fator, evidencia-se que a implantação da Governança na UFC assim é percebida pelos envolvidos na pesquisa: os gestores pesquisados, quanto ao Fator 1, 67,7\% não concordam que a implantação da Governança na UFC tenha produzido melhorias na gestão da Instituição. Por outro lado, destaca-se que essa percepção dos gestores ainda está em desenvolvimento, pois o processo é recente e está muito concentrado, ainda, na mudança de cultura.

Quanto ao Fator 2, 51,3\% não concordam que as estratégias de divulgação/implantação do processo de Governança tenham produzido efeitos positivos, enquanto $28,3 \%$ não souberam opinar quanto a essa influência. Essa afirmação apontou para um nível de conhecimento sobre Governança ainda incipiente dos gestores; possível falta de partilhamento de informações entre dirigentes e liderados; e sugeriu que a divulgação pode ter sido insatisfatória.

Por último, quanto ao Fator 3, totalizam $45 \%$ os que concordam que na implantação do processo de governança houve envolvimento dos agentes, enquanto $43 \%$ não souberam opinar. Esse resultado aponta certa inconsistência, pois o envolvimento da gestão é um fator propulsor da governança; identifica-se que o nível de envolvimento declarado não se coaduna com as percepções dos fatores 1 e 2 . Os respondentes, que são ao mesmo tempo gestores e integrantes do Comitê de Governança, aparentemente não se viam como engrenagem do processo. De certo modo, 
o fato de cerca de metade deles não saber opinar sobre o envolvimento dos gestores (fator 3) elucida porque as melhorias (fator 1) e a divulgação (fator 2) foram consideradas incipientes.

Evidencia-se como fator crítico o baixo nível de percepção dos gestores da UFC a respeito da Governança, bem como do processo de implantação e de publicidade. Infere-se que os gestores não perceberam os esforços administrativos e normativos da UFC que estavam em conformidade com a IN Conjunta CGU/MP No 001/2016. Sobre essa baixa percepção dos gestores a respeito do processo de implantação da Governança na UFC, levantam-se algumas inferências:

a) A baixa percepção sobre as vantagens e benefícios da implantação da Governança na UFC está relacionada a uma percepção dissociada que separa, de um lado, a figura do gestor e, de outro, a de integrantes das Câmaras do Comitê de Governança. Isso porque os respondentes são os integrantes do Comitê de Governança, sendo, portanto, os próprios responsáveis pelos resultados que a Governança pode trazer para a Instituição.

b) A baixa percepção sobre as melhorias que a Governança traz, está relacionada com o fato de existirem duas Câmaras no Comitê de Governança, que sugerem uma compartimentação na Administração e implica restrição a uma visão global a respeito do processo.

Assim, pela análise indutiva, destacam-se como fatores de sucesso, no processo de implantação da Governança na UFC, as seguintes ações administrativas: a existência de um planejamento estratégico, que é o PDI, elaborado dialogado e coletivamente; implantação formal da estrutura de Governança; campanha de divulgação do processo de Governança; articulação do processo de governança pela própria Secretaria de Governança sob o comando do Comitê. Ademais, indica-se como pontos de sucesso a elaboração de um quadro normativo que criou o Comitê de Governança, a Secretaria de Governança e a Política de Governança. 


\section{CONCLUSÃO}

Atingiu-se o objetivo geral de analisar a implantação da Governança na UFC, bem como foram alcançados os objetivos específicos, no primeiro, com a descrição do processo de Governança já realizado na UFC, que conduziram à investigação de instruções normativas, decretos, resoluções, portarias, atas e planos que trataram sobre a criação, organização e execução da Governança na UFC. No mesmo esteio, com o segundo objetivo, buscou-se conhecer a percepção dos gestores acerca do processo de Governança, aplicando-se um questionário entre os integrantes do Comitê de Governança.

Dentre os principais pontos levantados sobre a descrição do processo de Governança, destaca-se que a Universidade já contava com alguns elementos e significativos resultados de Governança, mas a implantação desta na Universidade Federal do Ceará ocorreu por meio de uma série de normas específicas, oriundas, a princípio, da necessidade de atender aos órgãos de controle, mas indo além do exigido, inclusive com a definição de uma estrutura organizacional que criou a Secretaria de Governança, na categoria de órgão suplementar, vinculada ao Gabinete do Reitor, o que indicou ação notável frente a outros órgãos públicos. Ademais, a Secretaria de Governança estabeleceu um Plano de Ação orientado pelo PDI, visando à implementação efetiva da Governança na UFC.

Outro ponto levantado é que a UFC adotou o modelo de Governança por resultados, quando estabeleceu a necessidade de indicadores e metas para as ações estratégicas de todas as unidades, visando avaliar os resultados alcançados e consequentemente avaliar se seus serviços estão agregando valor para o usuário cidadão. A dinâmica foi de que os objetivos estratégicos se desdobrem em objetivos táticos e operacionais e haja a efetiva realização da estratégia. Entende-se ser uma escolha acertada, porque assegura a elevação da confiabilidade da instituição perante a sociedade. 
Além da análise do processo de implementação da Governança, foi necessário considerar alguns aspectos da realidade na qual a Universidade está inserida para a conclusão dessa investigação, quais sejam, o significativo orçamento que tem a administrar, a ameaça constante do contingenciamento de recursos, a grande dimensão da instituição que conta com uma notória diversidade em termos de áreas e cursos, a dispersão geográfica dos campi; bem como a inexistência de modelos de Governança, o que dificulta à UFC se basear em experiências já acumuladas de instituições federais de ensino superior, tendo em vista que é um processo novo no qual todas estão mais ou menos no mesmo patamar de desenvolvimento.

Salienta-se que no PDI foram encontradas poucas ações, em termos de Governança, voltadas para o Eixo de ensino e muitas para o Eixo gestão. Acredita-se que em relação a esse documento de formulação coletiva ainda havia uma dificuldade por parte da comunidade em entender que a Governança perpassa todos os aspectos da Universidade e não apenas da gestão.

No tocante ao segundo objetivo específico, o de identificar a percepção dos gestores acerca do processo de Governança na UFC, o questionário permitiu entender um pouco das peculiaridades e contribuir significativamente para as conclusões aqui esboçadas.

Destaca-se que foi testada e rejeitada a $\mathrm{H} 0$ e confirmada a hipótese H1, de não haver distintas percepções dos gestores, seja por faixa etária, gênero, nível de escolaridade, área de atuação, tempo de trabalho na instituição e tempo de trabalho na função exercida. Isso porque não houve diferenças significativas nas respostas desses gestores pesquisados, considerando qualquer dessas variáveis. Aqui reside um ponto de especial atenção da Alta Administração porque a homogeneidade das respostas aponta para a baixa percepção generalizada em relação ao processo.

De forma geral, destaca-se que a Secretaria de Governança constitui fator de sucesso para a Governança na UFC, porquanto é um lócus 
que pensa e instrumentaliza a governança nessa instituição. Por sua vez, o tamanho e a diversidade da UFC constituem um fator crítico, pois dificultam a implantação de uma cultura de Governança.

Respondendo ao problema da pesquisa, elencam-se como fatores de sucesso para o processo de implantação da Governança na Universidade Federal do Ceará o aspecto normativo e estrutural criado para apoiar a Governança; a ação educativa dos órgãos de controle, quando explicitam a importância dessa para a continuidade das instituições públicas e incremento da confiança pública, o empoderamento da sociedade, bem como, internamente, todo um processo anterior que trazia elementos já consolidados e importantes para uma boa governança. Salienta-se, também, a forma como o sistema vem sendo implantado, de forma gradual, buscando conscientizar, mudar a cultura e angariar apoio e adesão de todos os segmentos.

Como fatores críticos, estão um conhecimento mais amplo do assunto, que via de regra é vinculado a exigências dos órgãos de controle; as distintas realidades da Universidade que se configuram nas distâncias geográficas que causam, entre outros problemas, a assimetria de informações e oportunidades; as vocações distintas, das áreas do conhecimento e distintos anseios dos segmentos que a compõem. Ademais, as resistências às inovações e à mudança de cultura se sobressaem no contexto dos fatores críticos, pelo que mostrou a pesquisa.

Conclui-se que a Universidade Federal do Ceará dispõe de todas as condições para o êxito do processo de implantação da Governança, dado o esforço que a sua gestão vem empreendendo. O elemento-chave, contudo, são as pessoas, porquanto são elas que incorporam a cultura organizacional, na qual se insere a Governança. Essas precisam ser formadas, motivadas e envolvidas para que não se tornem antagonistas do processo, de forma que os agentes se assumam corresponsáveis pelo êxito desta empreitada. 
Por fim, acredita-se que este estudo servirá de guia para essa e outras universidades públicas que busquem lograr êxito na implantação da governança, mormente porque destaca o papel-chave dos envolvidos e a necessidade de conhecer as especificidades de ambiente e cultura tão diferenciados, como é o caso das Universidades, além de permitir a discussão de modelos conceituais. Notadamente, as conclusões alcançadas são limitadas à instituição pesquisada, pelo que se sugere que estudos futuros envolvam outras Universidades, incluam os servidores técnico-administrativos ou mesmo seja feito um acompanhamento sistemático dessa percepção na própria Universidade Federal do Ceará para validação do modelo adotado.

\section{REFERÊNCIAS}

ALCÂNTARA, S. M. M. Controle interno. In: GUERRA, E. M.; CASTRO, S. H. R. (coord.). Controle externo: estudos temáticos. Belo Horizonte: Fórum, 2012. p. 115-131.

BARBOSA, C. R. Governança no setor público: um estudo sobre a aplicação dos princípios do modelo do PSC/IFAC na administração direta do estado de goiás. 2017. Dissertação (Mestrado em Administração) - Centro Universitário Alves Faria, Goiânia, 2017. Disponível em: https://bit. ly/2LgSkL9. Acesso em: 4 dez. 2017.

BORGES, A. Governance and educational policy: the recent agenda of world bank. Revista Brasileira de Ciências Sociais, São Paulo, v. 52, n. 18, p. $125-138,2003$.

BRASIL. Decreto n ${ }^{\circ}$ 9.203/2017, de 22 de novembro de 2017. Dispõe sobre a política de governança da administração pública federal direta, autárquica e fundacional. Diário Oficial da União, Brasília, DF, 23 nov. 2017. 
BRASIL. Ministério do Planejamento, Orçamento e Gestão. Instrução Normativa Conjunta MP/CGU no 1 , de 10 de maio de 2016. Dispõe sobre controles internos, gestão de riscos e governança no âmbito do poder executivo federal. Brasília, DF: Controladoria Geral da União. Disponível em: https://bit.ly/3eCrDLH. Acesso em: 15 ago. 2017.

BRASIL. Tribunal de Contas da União. Governança pública: referencial básico de governança aplicável a órgãos e entidades da administração pública e ações indutoras de melhoria. Brasília, DF: TCU, 2014.

CALMON, P.; COSTA, A. T. M. Redes e governança das políticas públicas. Revista de Pesquisa em Políticas Públicas, Brasília, DF, n. 1, p. 1-29, 2013.

CASTRO, D. P. Auditoria, contabilidade e controle interno no setor público: integração das áreas do ciclo de gestão; planejamento, orçamento, finanças, contabilidade e auditoria e organização dos controles internos, como suporte à governança corporativa. 6. ed. São Paulo: Atlas, 2015.

COUTO, R. M. Governança em instituições de nível superior: análise dos mecanismos de governança na universidade federal de Santa Catarina à luz do modelo multilevel governance. 2018. Dissertação (Mestrado em Engenharia) - Universidade Federal de Santa Catarina, Florianópolis, 2018. Disponível em: https://bit.ly/3oyXwIq. Acesso em: 10 ago. 2020.

COZZOLINO, L. F. F.; IRVING, M. A. Por uma concepção democrática de governança para a esfera pública. Revista Políticas Públicas, São Luís, v. 19, n. 2, p. 497-508, 2015. Disponível em: https://bit.ly/2VKLa3K. Acesso em: 10. ago. 2020. 
DI PIETRO, M. S. Z. Direito administrativo. São Paulo: Atlas, 2015.

EDWARDS, M.; HALligan, J.; HORRIGAN, B.; NICOLL, G. Public sector governance in Australia. Canberra: ANU, 2012.

FONTES FILHO, J. Rubens. Da nova gestão pública à nova governança pública: as novas exigências de profissionalização da função pública. In: CONGRESO INTERNACIONAL DEL CLAD SOBRE LA REFORMA DEL ESTADO Y DE LA ADMINISTRACIÓN PÚBLICA, 9., 2014, Quito. Anais [...]. Caracas: Clad, 2014.

GEORGE, D.; MALLERY, P. SPSS for Windows step by step: a simple guide and reference, 14.0 update. 7. ed. Boston: Allyn \& Bacon, 2006.

INSTITUTO BRASILEIRO DE GOVERNANÇA CORPORATIVA. Código das melhores práticas de governança corporativa. 4. ed. São Paulo: IBGC, 2009. Disponível em: https://bit.ly/37JSL8e. Acesso em: 15 set. 2019.

INSTITUTO BRASILEIRO DE GOVERNANÇA CORPORATIVA. Governança corporativa, Origem da governança e linha do tempo. São Paulo: IBGC, 2018.

JENSEN, M. C.; MECKLING, W. H. Theory of the firm: managerial behaviour, agency costs and ownership structure. Journal of Financial Economics, Amsterdam, v. 3, n. 4, p. 305-360, 1976.

LIMA NETO, D. Governança corporativa em administração pública: o caso brasileiro. Administradores, [s. 1.], 23 abr. 2011. Disponível em: https://bit.ly/33NExBZ. Acesso em: 20 mar. 2018. 
MAIA, J. L; DI SERGIO, L. C. Governança corporativa e estratégia empresarial: mapeamento bibliométrico da produção na área. Revista Gestão \& Tecnologia, Pedro Leopoldo, v. 17, n. 2, p. 160-185, 2017.

MARTINS, H. F.; MARINI, C. Governança para resultados: atributos ideais de um modelo. 2010. In: CONGRESSO CONSAD DE GESTÃO PÚBLICA, 3., 2010, Brasília, DF. Anais [...]. Brasília, DF, 2010. Disponível em: https://bit.ly/34XbMnF. Acesso em: 15 out. 2018.

MATIAS-PEREIRA, J. A governança corporativa aplicada no setor público brasileiro. Administração Pública e Gestão Social, Viçosa, v. 2, n. 1, p. 109-134, 2010. Disponível em: https://bit.ly/311qIXw. Acesso em: 18 out. 2017.

MATOS, F.; DIAS, R. Governança: questões conceituais sobre processos de tomada de decisão, redes de formulação e deliberação sobre políticas de recursos hídricos. In: CONGRESO INTERNACIONAL DEL CLAD SOBRE LA REFORMA DEL ESTADO Y DE LA ADMINISTRACIÓN PÚBLICA, 2013, Montevideo. Anais [...]. Caracas: Clad, 2013.

MEIRELLES, H. L. Direito administrativo brasileiro. 28. ed. São Paulo: Malheiros, 2003.

MEIRINHO, A. F. Gestão pública para resultados e indicadores de desenvolvimento sustentável. Para Onde?, Porto Alegre, v. 8, n. 2, p. 114-122, 2014.

MOREIRA NETO, D. F. Governo e governança em tempo de mundialização: reflexões à luz dos novos paradigmas do direito. Revista de Direito Administrativo, Rio de Janeiro, v. 23, n. 4, p. 425-429, 2007. 
NTIM, C. G.; SOOBAROYEN, T.; BROAD, M. J. Governance structures, voluntary disclosure and public accountability: the case of UK higher education institutions. Accounting, Auditing \& Accountability Journal, Bingley, v. 30, n. 1, p. 65-118, 2017. Disponível em: https://bit.ly/33ONkne. Acesso em: 10 ago. 2020.

OECD. Governance of state-owned enterprises: guidelines on the corporate. Paris: OECD, 2005. Disponível em: https://bit.ly/33QAhSh. Acesso em: 20 dez. 2017.

OLIVEIRA, A. G.; PISA, B. J. IGovP: índice de governança pública: instrumento de planejamento do estado e de controle social pelo cidadão. Revista de Administração Pública, Rio de Janeiro, v. 39, n. 5, p. 12631290, 2015. Disponível em: https://bit.ly/39R3wZg. Acesso em: 10 ago. 2020.

OLIVEIRA, R. Gestão pública: democracia e eficiência: uma visão prática e política. Rio de Janeiro: FGV, 2012.

RIBEIRO, R. M. C. Os desafios contemporâneos da gestão universitária: discursos politicamente construídos. In: CONGRESSO IBERO-AMERICANO DE POLÍTICA E ADMINISTRAÇÃO DA EDUCAÇÃO, 4., 2014, Porto, 2014. Anais [...]. Porto: Anpae, 2014. p. 1-14. Disponível em: https://bit.ly/3jRLes4. Acesso em: 12 set. 2020.

RIBEIRO, S. M. R. Controle interno e paradigma gerencial. Brasília, DF: Enap, 1997.

RODRIGUES, C. A. Governança para resultados: estudo de caso em uma empresa pública de tecnologia da informação. 2015. Dissertação (Mestrado profissional em Administração Pública) - Escola Brasileira de 
Administração Pública e de Empresas, Fundação Getúlio Vargas, Rio de Janeiro, 2015. Disponível em: https://bit.ly/3erDSKJ. Acesso em: 25 out. 2018.

RODRIGUES, J. G. L. Princípios para boa governança pública. [S. 1.: s. n.], 2014.

RONCONI, L. Governança pública: plataforma democrática. [S. l.: s. n.], 2011.

SILVA, E. A.; PEREIRA, J. R.; ALCÂNTARA, V. C. Interfaces epistemológicas sobre administração pública, institucionalismo e capital social. Cadernos EBAPE.BR, Rio de Janeiro, v. 10, n. 1, p. 20-39, 2012.

SILVA, F. R.; CANÇADO, A. C.; SANTOS, J. C. Compreensões acerca do conceito de controle social. Desenvolvimento em Questão, Ijuí, v. 15, n. 41, p. 24-58, 2017. Disponível em: https://bit.ly/3oRiBz3. Acesso em: $1^{\circ}$ nov. 2017

SILVEIRA, A. M. Governança corporativa no Brasil e no mundo: teoria e prática. 2. ed. Rio de Janeiro: Elsevier, 2015.

TRAVAGLIA, K. R.; CÉSAR, C. S. A importância do controle interno como instrumento de governança pública. Revista Técnica dos Tribunais de Contas, Belo Horizonte, n. 1, 2016. Disponível em: https://bit. ly/31Q2leH. Acesso em: 25 nov. 2017.

UNIVERSIDADE FEDERAL DO CEARÁ. A universidade. Fortaleza: UFC, 2017. Disponível em: https://bit.ly/3gmKFGw. Acesso em: 20 dez. 2017. 
UNIVERSIDADE FEDERAL DO CEARÁ. Plano de desenvolvimento institucional (PDI) 2018-2022 da UFC. Fortaleza: UFC, 2018. Disponível em: https://bit.ly/3erUy4M. Acesso em: 10 ago. 2018.

UNIVERSIDADE FEDERAL DO CEARÁ. Portaria n⿳4 4.117 do Reitor da UFC, de 27 de setembro de 2017. Institui a política de governança da Universidade Federal do Ceará. Fortaleza: UFC, 2017. Disponível em: https://bit.ly/3oZj42f. Acesso em: 10 ago. 2017.

UNIVERSIDADE FEDERAL DO CEARÁ. Resolução n* 1 do Conselho Universitário (Consuni) da UFC, de 20 de janeiro de 2017. Cria a Secretaria de Governança, órgão suplementar subordinado à Reitoria. Fortaleza: UFC, 2017. Disponível em: https://bit.ly/2TT9m2V. Acesso em: 10 ago. 2017.

UNIVERSIDADE FEDERAL DO CEARÁ. Resolução 34 do Conselho Universitário (Consuni) da UFC de 19 de maio de 2017. Cria o Comitê de Governança com o objetivo de elaborar e aprovar proposta de execução de uma política de gestão administrativa que envolva todos os órgãos integrantes da estrutura organizacional da UFC, na Capital e no interior do Estado. Fortaleza: UFC, 2017. Disponível em: https://bit.ly/3euoVI2. Acesso em: 10 ago. 2017.

UNIVERSIDADE FEDERAL DO CEARÁ. UFC passa de terceiro a segundo lugar em ranking da transparência nacional. UFC, Fortaleza, 16 jul. 2018. Disponível em: https://bit.ly/2I8I1ac. Acesso em: 20 dez. 2018. 